\title{
ECONOMIC STRUCTURE ANALYSIS, LEADING SECTORS AND \\ REGIONAL DEVELOPMENT IN MALANG YEAR 2008-2012.
}

\author{
Oleh: \\ Seno Aji Santoso \\ PT. Gudang Garam, Tbk. \\ E-mail : -
}

\begin{abstract}
The purpose of this study was to determine the structure of the economy, the dominant sector and regional development strategies in Malang Year 20082012.From the analysis it can be concluded that by using a tool known for Economic Structural Analysis of 9 existing economic sector in Gross Domestic Product during the years 2008 to 2012 the sector that contributes most to the Gross Domestic Product (GDP) at constant prices Malang is the sector tertiary contributing $64.82 \%$. From the analysis of the leading sectors, Malang has a leading sectors are trade, hotels, and restaurants with LQ value of 1.29 and a differential value shift by shift proportional 195,272.27 and 135,101.68. From the analysis of gravity, Malang has the greatest interaction with the Malang region. For the development of Malang area is quite well characterized by an increase in Gross Domestic Product (GDP) from year to year but still needs to be developed further other economic sectors that still have the potential to compete with other regions in East Java.

Keywords : Economic Structure, Leading Sector, Regional Development
\end{abstract}

\begin{abstract}
ABSTRAK
Tujuan dari penelitian ini adalah untuk mengetahui struktur perekonomian, sektor unggulan dan strategi pengembangan wilayah di Kota Malang Tahun 20082012.Dari hasil analisis dapat disimpulkan bahwa dengan menggunakan alat Analisis Struktur Perekonomian diketahui dari 9 sektor ekonomi yang ada di Produk Domestik Regional Bruto selama tahun 2008-2012 sektor yang memberikan kontribusi terbanyak terhadap Produk Domestik Regional Bruto (PDRB) atas dasar harga konstan Kota Malang adalah sektor tersier dengan kontribusi 64,82\%. Dari hasil analisis sektor unggulan, Kota Malang memiliki satu sektor unggulan yaitu sektor perdagangan, hotel, dan restoran dengan nilai LQ 1,29 serta nilai differential shift 195.272,27 dan proportional shift sebesar 135.101,68. Dari analisis gravitasi, Kota Malang memiliki interaksi paling besar dengan wilayah Kabupaten Malang. Untuk pengembangan wilayah Kota Malang sudah cukup baik ditandai dengan peningkatan Produk Domestik Regional Bruto
\end{abstract}


(PDRB) dari tahun ketahun akan tetapi masih perlu dikembangkan lagi sektorsektor ekonomi lain yang masih memiliki potensi agar bisa bersaing dengan wilayah lain yang ada di Jawa Timur.

Kata Kunci : Struktur Ekonomi, Sektor Unggulan. Pengembangan Wilayah

\section{PENDAHULUAN}

Indonesia merupakan negara yang berkembang, memiliki jumlah penduduk yang besar, dan memiliki kekayaan alam yang melimpah. Tentunya untuk memajukan perekonomian Indonesia diperlukan suatu pembangunan.

Pembangunan adalah suatu proses yang beruntun dengan memiliki tujuan akhir agar meningkatkan kesejahteraan masyarakat. Oleh karena itu, strategi dari pembangunan harus diperhatikan baik dibidang produksi maupun infrastruktur utnuk meningkatkan pertumbuhan ekonomi serta peningkatan kualitas dari sumber daya manusia (SDM). Dengan tujuan dan strategi pembangunan tesebut, maka pelaksanaan agar diarahkan di bidang - bidang yang dapat meningkatkan kesejahteraan masyarakat.

Tolak ukur dari kebehasilan dari pembangunan suatu wilayah dengan mengukur tingkat pertumbuhan ekonomi wilayah tersebut. Pertumbuhan ekonomi ialah proses suatu perekonomian berkembang dari waktu ke waktu. Pembangunan selalu menimbulkan dampak positif maupun negatif, oleh sebab itu sangat diperlukan suatu indikator sebagai tolak ukur untuk menilai keberhasilan pembangunan. Paradigma mengenai pembangunan cenderung mengidentikkan pembangunan dikatakan berhasil bila pertumbuhan ekonomi disuatu wilayah relatif tinggi. Pembangunan nasional yang diarahkan pada pembangunan daerah, berdasarkan UU 32 tahun 2004 pada dasarnya adalah untuk memacu pemerataan pembangunan dan menambah kesejahteraan rakyat. Dimana perlu pendayagunaan potensi daerah secara optimal dan terpadu. Sehingga upaya pemerataan pembangunan diseluruh tanah air mulai dari daerah maju, berkembang dan terpencil perlu untuk ditingkatkan demi tercapainya 
pengembangan wilayah secara nasional.

Untuk memacu laju pertumbuhan ekonomi regional serta meningkatkan kontribusinya terhadap pembentukan total Produk Domestik Regional Bruto (PDRB), maka pembangunan sektor unggulan dapat dijadikan sebagai penggerak pembangunan ekonomi. Secara umum tujuan pembangunan bidang ekonomi khususnya sektor unggulan adalah untuk mempercepat laju pertumbuhan ekonomi dengan demikian dapat tercipta stabilitas ekonomi yang sehat dan dinamis, dan tercipta kemakmuran dan kesejahteraan yang dinikmati oleh masyarakat daerah tersebut.

Di tingkat regional, pengembangan wilayah yang ditinjau dari aspek ekonomi harus menjadi prioritas utama dalam menggerakkan ekonomi nasional. Sebagai contoh, Propinsi Jawa Timur yang secara terus-menerus memetakan potensi ekonomi dalam memajukan pengembangan wilayah, mengingat potensi ekonomi regional yang ada di Propinsi Jawa Timur sangat besar.
Potensi ekonomi yang paling utama adalah sektor pertanian, industri pengolahan, dan perdagangan.

Kota Malang merupakan kota terbesar kedua di Jawa Timur setelah Surabaya dan memiliki jumlah penduduk terbesar kedua di Jawa Timur. Kota Malang dapat dikatakan memiliki PDRB yang baik, karena selama kurun waktu lima tahun terakhir pertumbuhan PDRB terus mengalami peningkatan. Untuk itu, pengembangan suatu wilayah harus melihat dengan jelas struktur ekonomi guna menjadi prioritas Pemerintah Kota Malang, untuk memanfaatkan dan meningkatkan sektor unggulan. Selama ini banyak sektor atau potensi wilayah di Kota Malang belum digunakan dan diekplorasi secara maksimal. Dengan berbagai dukungan dari semua elemen masyarakat dan Pemerintah daerah, diharapkan pembangunan wilayah Kota Malang dapat menjadi lebih baik.

Dalam rangka pengembangan potensi wilayah yaitu dengan melakukan identifikasi terhadap potensi sektor kegiatan ekonomi yang dimiliki dan identifikasi kinerja 
ekonomi wilayah dengan menganalisis pertumbuhan ekonomi wilayah dan mengukur sektor ekonomi mana saja yang menjadi sektor basis di daerah Kota Malang, dalam analisis ini menggunakan analisis Location question (LQ), analisis Shift Share, analisis Gravitasi dan analisis SWOT.

Oleh karena itu, guna mewujudkan kemajuan pembangunan di Kota Malang maka penelitian ini mengambil judul "Analisis Struktur Perekonomian, Sektor Unggulan Dan Pengembangan Wilayah Di Kota Malang Tahun 2008-2012" untuk mengetahui struktur perekonomian, sektor unggulan dan pengembangan wilayah di kota Malang agar dapat menentukan kebijakan yang tepat untuk dapat di ambil oleh pemerintah Kota Malang dalam pembangunan.

\section{METODE PENELITIAN}

Penelitian ini difokuskan di Kota Malang yang terletak pada provinsi Jawa Timur, alasan memilih penelitian di Kota Malang karena memiliki Kota Malang dapat dikatakan memiliki PDRB yang baik, karena selama kurun waktu lima tahun terakhir pertumbuhan PDRB terus mengalami peningkatan dan merupakan salah satu wilayah yang berkembang terutama perkembangan pada setiap sektor ekonomi di Kota Malang sehingga penelitian diharapkan dapat memberikan gambaran yang lengkap tentang kondisi ekonomi wilayah di Kota Malang.

Jenis penelitian ini adalah Deskriptif kuantitatif. Jenis data yang digunakan dalam penelitian ini adalah data sekunder yang berbentuk data tahunan (time series data). Adapun data sekunder yang digunakan yaitu Produk Domestik Regional Bruto (PDRB) tahun 20082012 dan Jumlah Penduduk tahun 2008-2012 Di Wilayah kota Malang dan Provinsi Jawa Timur

Adapun teknik pengumpulan data yang digunakan penulis dalam penelitian ini adalah Studi Kepustakaan yaitu metode pengumpulan data atau informasi dengan menelusuri literatur yang ada baik berupa buku, arsip, jurnal, penelitian sebelumnya dan lain sebagainya dan Dokumentasi yaitu 
Teknik pengumpulan data menggunakan studi dokumentasi yang dilakukan untuk memperoleh data sekunder. Data sekunder antara lain mencakup dokumen-dokumen resmi, buku-buku dan hasil-hasil penelitian yang berwujud laporan. Metode yang digunakan dalam penelitian ini antara lain adalah 1) Analisis Struktur Perekonomian dilakukan dengan Menggunakan Tabel Produk Domestik Regional Bruto (PDRB) atas dasar harga berlaku dan Produk Domestik Regional Bruto (PDRB) atas dasar harga Konstan yang diolah menjadi bentuk prosentase agar dapat mengetahui kontribusi tiap sektor terhadap Produk Domestik Regional Bruto. 2) Analisis Sektor Unggulan dengan menggunakan Location Quotient dan Shift share. Location Quotient digunakan untuk menentukan kategori suatu sektor termasuk dalam sektor yang berpotensi atau sektor unggulan atau sektor bukan unggulan

Dimana:

$$
\mathrm{LQ}=\frac{S_{i k} / P D R R_{k}}{S_{i p} / P D R R_{P}}
$$

$\mathrm{S}_{\mathrm{ik}}=$ Jumlah PDRB sektor/subsektor ekonomi i (Jawa Timur)

$\mathrm{S}_{\mathrm{ip}}=$ Jumlah PDRB seluruh sektor/subsektor wilayah $p$ (Kota Malang)

PDRRk = Jumlah total PDRB wilayah $k$ (Jawa Timur)

PDRR $_{\mathrm{p}}=$ Jumlah total PDRB wilayah $p$ (Kota Malang)

Lalu analisis Shift Share yang digunakan untuk mengetahui perubahan dan pergeseran sektor atau industri pada perekonomian regional maupun lokal. Analisis Shift-share menggambarkan kinerja sektor-sektor di suatu wilayah dibandingkan dengan perekonomian nasional. Bila suatu daerah memperoleh kemajuan sesuai dengan kedudukannya dalam perekonomian nasional, maka akan dapat ditemukan adanya shift (pergeseran) hasil pembangunan perekonomian daerah. metode analisis Shift Share diawali dengan mengukur perubahan PDRB suatu sektor - i di suatu region - j (Dij) dengan formulasi $\mathrm{Dij}=\mathrm{Nij}+$ $\mathrm{Mij}+\mathrm{Cij}$.

Di mana:

Keterangan : 
$\mathrm{Nij}=\mathrm{Eij} \cdot \mathrm{rn}$

$\mathrm{Mij}=\mathrm{Eij}($ rin-rn)

$\mathrm{Cij}=\mathrm{Eij}($ rij-rn)

sedangkan rn dan rin masing masing adalah laju

pertumbuhan agregat provinsi dan pertumbuhan sektor/subsektor i provinsi, yang masing-masing dapat didefinisikan sebagai berikut:

rij $=(E i j, t-E i j) / E i$

rin $=($ Ein,$t-$ Ein $) /$ Ein

$\mathrm{rn}=(\mathrm{En}, \mathrm{t}-\mathrm{En}) / \mathrm{En}$

Keterangan:

Di,j = Perubahan PDRB sektor (subsektor) i di Kota Malang (Rp.),

$\mathrm{Ni}, \mathrm{j}=$ Perubahan PDRB sektor (subsektor) i di Kota Malang yang disebabkan oleh pengaruh pertumbuhan ekonomi secara regional Provinsi Jawa Timur (Rp.) Mi,j = Perubahan PDRB sektor (subsektor) i di Kota Malang yang disebabkan oleh pengaruh pertumbuhan sektor (subsektor) i secara regional Provinsi Jawa Timur (Rp.)

Ci,j = Perubahan PDRB sektor (subsektor) i di Kota Malang yang disebabkan oleh keunggulan pangsa wilayah sektor (subsektor) tersebut di Kota Malang (Rp.)
Eij $=$ PDRB sektor/subsektor $\mathrm{i}$ di Kota Malang tahun awal analisis (Rp.)

Ein $=$ PDRB sektor/subsektor $\mathrm{i}$ di Jawa Timur tahun awal analisis (Rp.) En $=$ PDRB total di Provinsi Jawa Timur tahun awal analisis (Rp.)

Eij,t $=$ PDRB sektor/subsektor i di Kota Malang tahun akhir analisis (Rp.)

Ein,t $=$ PDRB sektor/subsektor $\mathrm{i}$ di Jawa Timur tahun akhir analisis (Rp.)

En,t $=$ PDRB total di Provinsi Jawa Timur tahun akhir analisis (Rp.)

3) Lalu Metode Analisis Pengembangan Wilayah dengan menggunakan analisis gravitasi dan analisis SWOT. Analisis gravitasi digunakan untuk mencari wilayah di sekitar kota yang berpotensi kuat dalam pertumbuhannya. Adanya interaksi antara kabupaten-kota menunjukkan eratnya hubungan antara wilayah 1 dengan wilayah 2 sebagai konsekuensi interaksi kota desa dalam teori pusat pertumbuhan. Adapun rumus untuk menghitung interaksi dalam hubungan desa-kota adalah:

$$
\mathrm{I} 1,2=\mathrm{a}(\mathrm{W} 1 \mathrm{P} 1)(\mathrm{W} 2 \mathrm{P} 2) / \mathrm{Jb} 12
$$


Keterangan :

I1,2 : Interaksi dalam wilayah 1 dan 2

W1 : pendapatan perkapita wilayah 1

W2 : pendapatan perkapita wilayah 2

P1 : Jumlah penduduk wilayah 1

P2 : Jumlah penduduk wilayah 2

$\mathrm{J} 1,2$ : jarak antara wilayah 1 dan 2 (dalam meter)

a : konstanta yang nilainya 1

b : konstanta yang nilainya 2 .

Nilai I1,2 , menunjukkan eratnya hubungan antara wilayah 1 dan 2 , semakin besar nilai I1,2, maka semakin erat hubungan antara dua wilayah.

Lalu analisis SWOT dalam penelitian ini mengkaji fenomena secara kualitatif tentang faktor faktor kekuatan, kelemahan, peluang dan ancaman pembangunan ekonomi Kota Malang dalam bentuk tabel guna memudahkan dalam pengambilan kebijakan.

\begin{tabular}{|l|l|l|}
\hline \multicolumn{1}{|c|}{ Internal } & $\begin{array}{l}\text { STRENGTH (S) } \\
\text { Daftar Kekuatan } \\
\text { Internal }\end{array}$ & $\begin{array}{l}\text { WEAKNESS (W) } \\
\text { Daftar Kelemahan } \\
\text { Internal }\end{array}$ \\
\hline $\begin{array}{l}\text { OPPORTUNITIES (O) } \\
\text { Daftar Peluang } \\
\text { Eksternal }\end{array}$ & $\begin{array}{l}\text { STRATEGI S-O } \\
\text { Gunakan kekuatan untuk } \\
\text { memanfaatkan peluang }\end{array}$ & $\begin{array}{l}\text { STRATEGI W-O } \\
\text { Mengatasi kelemahan } \\
\text { dengan memanfaatkan } \\
\text { peluang }\end{array}$ \\
\hline $\begin{array}{l}\text { THREATS (T) } \\
\text { Daftar Ancaman }\end{array}$ & $\begin{array}{l}\text { STRATEGI S-T } \\
\text { Gunakan kekuatan untuk } \\
\text { menghindari ancaman }\end{array}$ & $\begin{array}{l}\text { STRATEGI W-T } \\
\text { Meminimalkan } \\
\text { kelemahan dan } \\
\text { menghindari ancaman }\end{array}$ \\
\hline
\end{tabular}

Tabel 1. Matriks SWOT

\section{PEMBAHASAN}

Dari hasil penghitungan analisis struktur perekonomian kegiatan ekonomi yang mempunyai peranan terbesar selama lima tahun berturut-turut adalah sektor tersier yang menyumbangkan $63.68 \%$ pada tahun 2008, $64.37 \%$ pada tahun 2009, 65.09\% pada tahun 2010, $65.15 \%$ pada tahun 2011 dan $65.47 \%$ 
pada tahun 2012 dengan sumbangan terbesar diberikan oleh sektor perdagangan, hotel dan restoran sebesar $37.69 \%$ pada tahun 2008, $38.18 \%$ pada tahun 2009 , 38.79\% pada tahun $2010,41.17 \%$ pada tahun 2011 dan $41.82 \%$ pada tahun 2012. Kemudian diikuti dengan sektor sekunder yang selama lima tahun berturut-turut menyumbangkan $35.78 \%$ pada tahun 2008, 35.13\% pada tahun 2009, 34.66\% pada tahun 2010, 34.45\% pada tahun 2011 dan 34.17\% pada tahun 2012 dengan rata-rata $34.74 \%$. Sumbangan terbesar diberikan oleh sektor industri pengolahan sebesar $32.91 \%$ pada tahun $2008,32.13 \%$ pada tahun 2009, 31.39\% pada tahun 2010, $30.06 \%$ pada tahun 2011 dan $29.73 \%$ pada tahun 2012, sedangkan kontribusi terkecil di sumbang oleh sektor primer yang hanya menyumbangkan $0.54 \%$ pada tahun $2008,0.49 \%$ pada tahun $2009,0.45 \%$ pada tahun 2010, 0.39\% pada tahun 2011 dan $0.36 \%$ pada tahun 2012 dengan rata-rata $0.44 \%$. Sumbangan terbesar diperoleh dari sektor pertanian yaitu $0.48 \%$ pada tahun $2008,0.44 \%$ pada tahun $2009,0.41 \%$ pada tahun $2010,0.35 \%$ pada tahun 2011 dan $0.32 \%$ pada tahun 2012 .

Dari analisis sektor unggulan didapatkan hasil penghitungan dari analisis LQ Sektor yang memiliki nilai LQ paling besar terdapat pada sektor keuangan, persewaan, dan jasa perusahaan, dengan kisaran nilai LQ secara berturut-turut adalah 1.60, $1.63,1.41,1.39$, dan 1.37 dengan rata-rata LQ 1,48. Selanjutnya diikuti oleh sektor jasa dengan kisaran nilai LQ adalah1.38, 1.37, 1.47, 1.49, dan 1.48 dengan rata-rata 1.44 . Kemudian di ikuti oleh sektor perdagangan, hotel dan restoran dengan kisaran nilai LQ 1.27, 1.28, $1.31,1.30$, dan 1.28 dengan rata-rata 1.29. Lalu sektor unggulan yang terakhir adalah sektor industri pengolahan dengan kisaran nilai LQ $1.24,1.24,1.19,1.20$, dan 1.19. dengan rata-rata 1.21. Sedangkan sektor yang memiliki nilai koefisien LQ < 1, artinya sektor tersebut merupakan sektor non basis diantaranya adalah sektor bangunan dengan LQ secara berturut-turut 0,$76 ; 0,81 ; 0,83 ; 0,83$ dan 0,84 dengan rata-rata LQ 0,82. Kemudian diikuti oleh sektor listrik, gas dan air 
bersih sebesar 0,$29 ; 0,29 ; 1,25 ; 1,25$ dan 1,27 dengan rata-rata LQ 0,87. Lalu sektor angkutan/komunikasi sebesar 0,$72 ; 0,68 ; 0,45 ; 0,43$ dan 0,42 dengan rata-rata LQ 0,54. Kemudian sektor pertanian sebesar 0,$03 ; 0,03 ; 0,03 ; 0,02$ dan 0,02, dengan rata-rata LQ 0,03 dan sektor yang memiliki LQ terendah adalah sektor pertambangan sebesar 0,03 ; 0,$02 ; 0,02 ; 0,02$ dan 0,02 dengan rata-rata LQ 0,02. Selama kurun waktu 2008-2012 sektor yang memiliki nilai LQ paling kecil adalah sektor pertambangan dan pertanian. Dari analisis Shift Share Dengan melihat besaran Proportional Shift (PS) dan Differential Shift (DS), maka suatu daerah/sektor dapat dikategorikan menjadi empat kelompok / kuadran. Dengan menggunakan alat analisis Shift Share, dapat dilihat dari pendekatan DS dan PS sekaligus, pada periode 2008-2012 secara agregat posisi perekonomian (PDRB) Kota Malang terletak pada Kuadran III (PS negatif dan DS negatif). Hal ini menunjukkan bahwa secara agregat sektor ekonomi di Kota Malang dikategorikan sebagai sektor yang terbelakang dan berdaya saing lemah atau dikategorikan terbelakang. Hal ini berarti bahwa ekonomi Kota Malang mengalami pertumbuhan relatif lambat dibanding pertumbuhan Jawa Timur dan memiliki daya saing yang relatif rendah serta arah pertumbuhan ekonomi sektor dominan di Kota Malang tidak sejalan dengan arah pertumbuhan sektor dominan di tingkat Jawa Timur. Pada kuadran I (PS positif dan DS positif) ditempati oleh sektor perdagangan. Hal ini menunjukkan bahwa sektor tersebut berada pada posisi yang maju dan berkembang. sektor tersebut dikategorikan sebagai sektor yang memiliki laju pertumbuhan yang cepat dan mampu bersaing dengan sektor ekonomi di wilayah lain. Pada kuadran II (PS positif dan DS negatif) ditempati oleh sektor Angkutan dan komunikasi serta sektor Keuangan. Hal ini memberikan pengertian bahwa sektor-sektor tersebut berada pada posisi tertekan tapi sedang berkembang (developing). Sektorsektor tersebut dikategorikan sebagai sektor ekonomi yang memiliki laju 
pertumbuhan yang cepat, tetapi sektor tersebut tidak mampu bersaing dengan sektor ekonomi dari wilayah lain (daya saingnya rendah). Sementara itu, Pada kuadran III (PS negatif dan DS negatif) di tempati oleh sektor Pertanian, Pertambangan, dan Industri. Hal ini menunjukkan bahwa kelompok sektor ekonomi di Kota Malang tersebut dikategorikan sebagai sektor yang terbelakang dan berdaya saing lemah atau dikategorikan terbelakang. Di kuadran IV ditempati oleh sektor Listrik gas dan air berih serta sektor Jasa-jasa. Sektor ini mempunyai kecenderungan sebagai sektor yang tertekan tetapi berpotensi (highly potential). Sektor ini memiliki tingkat daya saing yang tinggi tetapi laju pertumbuhannya lambat.

Dari hasil analisis pengembangan wilayah menggunakan analisis gravitasi dan analisis SWOT. Dari analisis gravitasi dapat diketahui bahwa interaksi spatial terbesar adalah antara kota Malang dengan Kabupaten Malang dengan nilai ratarata $6,123,865,455,443,100,0$. Kemudian Kota Malang dengan Kota
Batu dengan nilai rata-rata 74,826,686,138,573,9. Lalu Kota Malang dengan Kota Kabupaten Pasuruan dengan nilai rata-rata 33,773,317,166,082,1. Dan interaksi spatial terendah adalah antara Kota Malang dengan Kabupaten Blitar dengan nilai rata-rata 14,058,172,551,818,5. Dari analisis SWOT dapat diketahui bahwa subsektor-subsektor yang termasuk tipologi I adalah subsektor listrik; restoran; sewa bangunan; jasa perorangan, dimana subsektorsubsektor tersebut merupakan subsektor basis sekaligus pertumbuhanya cepat sehingga dapat menjadi subsektor yang strategis sebagai kekuatan (strenght) perekonomian Kota Malang dan dapat dikembangkan lebih lanjut. Sedangkan subsektor-subsektor ekonomi yang termasuk tipologi II adalah subsektor Industri Makanan, Minuman, Tembakau; Air Bersih; Perdagangan; Angkutan Rel; Angkutan Jalan Raya; Lembaga Keuangan Bukan Bank; Jasa Perusahaan; Jasa Sosial Kemasyarakatan; Jasa Hiburan dan Kebudayaan. Subsektor ini 
mempunyai nilai LQ> 1 yang berarti

merupakan sektor basis namun perlu perhatian karena ancaman (threat) yang dihadapi adalah pertumbuhan yang lambat. Untuk tipologi III yaitu subsektor industri kertas, percetakan dan penerbitan; Konstruksi; Jasa Penunjang Angkutan; Komunikasi. Subsektor ini layak untuk dikembangkan dan merupakan peluang (oppurtunity) menjadi sektor basis berdasarkan pertumbuhan ekonomi yang cepat. Dan yang termasuk tipologi IV adalah subsektor Tanaman Bahan Makanan; Tanaman Perkebunan; Peternakan; Kehutanan;

Perikanan; Pertambangan Migas; Pertambangan Non Migas, Penggalian; Industri Tekstil, Pakaian Jadi dan Kulit; Industri Kayu dan Sejenisnya; Industri Kimia, Minyak Bumi, Karet dan Plastik; Industri Barang Galian non Logam Kecuali Minyak Bumi Dan Batu Bara; Industri Logam Dasar; Industri Barang dari Logam, Mesin dan Peralatan; Industri Pengolahan Lainnya; Gas Kota; Hotel; Angkutan Laut; Angkutan Penyebrangan; Angkutan Udara; Ban; Pemerintahan Umum.
Subsektor ini dianggap sebagai kelemahan (weakness) serta tidak berpotensi karena bukan sektor basis dan pertumbuhan ekonominya lambat.

\section{DAFTAR PUSTAKA}

Alkadri et.al. 1999. Tiga Pilar Pengembangan Wilayah. Jakarta: BPPT

Ambardi urbanus Dan sucia prihawantoro, 2002. Pengembangan Wilayah Dan Otonomi Daerah. Jakarta: BPPT

Arsyad. L., 1999. Pengantar Perencanaan dan Pembangunan Ekonomi Daerah (1sted). Yogyakarta: BPFE.

Badan Pusat Statistik Kota Malang. 2012. Kota Malang Dalam Angka. Malang: BPS Kota Malang

Badan Pusat Statistik Jawa Timur. 2012. Jawa Timur Dalam Angka. Surabaya: BPS Jawa Timur

Budiharsono, Sugeng. 2001. Teknik Analisis Pembangunan Wilayah Pesisir dan Lautan. Jakarta: Pradnya Pramita.

Kuncoro. M., 2002. Analisis Spasial dan Regional: Studi Aglomerasi dan Kluster Industri Indonesia. Yogyakarta: UPP-AMP YKPN. 
Rangkuti, Freddy. 2000. Analisis SWOT Teknik Membedah Kasus Bisnis. Jakarta: Gramedia Pustaka.

Soepono, Prasetyo. 1993. Analisis Shift Share Perkembangan dan Penerapan. Dalam Jurnal Ekonomi dan Bisnis Indonesia. Vol. VIII. No. 1. Hal 43-54. Yogyakarta: UGM.

Sukirno, Sadono. 1985. Ekonomi Pembangunan. Jakarta: Bagian Penerbit Fakultas Ekonomi Universitas Indonesia

Sukirno,Sadono, 1994. Pengantar Teori Ekonomi Makro. Jakarta: Raja Grafindo Persada.

Sumani, Sambodo. 2006. Ekonomi dan Manajemen Teknik. Yogyakarta: Graha Ilmu.

Suryana, 2000. Ekonomi Pembangunan: Problematika dan Pendekatan. Edisi Pertama, Jakarta: Salemba Empat.

Susanto, Arif dan Neni Woyanti. Analisis Sektor Potensial Dan Pengembangan Wilayah Guna Mendorong Pembangunan Di Kabupaten Rembang. Media Ekonomi dan Manajemen. Juli 2008.

Syafrizal, 1997. Pertumbuhan Ekonomi dan Ketimpangan
Regional Wilayah Wilayah Indonesia Bagian Barat. Jakarta: Prisma.

Tarigan, Robinson, 2005.Ekonomi Regional Teori dan Aplikasi. Jakarta: Bumi Aksara.

Tarigan,Robinson, 2009.Ekonomi Regional Teori dan Aplikasi Edisi Revisi. Jakarta: Bumi Aksara.

Todaro M.P. dan Stephen C. Smith, 2006. Pembangunan Ekonomi 1 Edisi 9. Jakarta: Erlangga.

Undang-Undang No. 32 Tahun 2004, Tentang Pemerintahan Daerah.

Undang-Undang No 33 Tahun 2004 Tentang Perimbangan Keuangan Antara Pemerintah Pusat dan Pemerintah Daerah.

Wijaya, Bayu dan Hastarini Dwi Atmanti, 2006. Analisis Pengembangan Wilayah Dan Sektor Potensial Guna Mendorong Pembangunan Di Kota Salatiga,Dinamika Pembangunan, Desember 2006.

Wiyadi dan Rina Trisnawati, 2002, Analisis Potensi Daerah Untuk Mengembangkan Wilayah Di Eks - Karesidenan Surakarta Menggunakan Teori Pusat Pertumbuhan, Fokus Ekonomi, Desember 2002, download. 
Economic Structure Analysis, Leading Sectors..........Seno Aji Santoso 